DOE/PC/95231-26

Dist. Category UC-112

UTSI 99-06

\title{
LIFE CYCLE COST STUDY FOR COATED CONDUCTOR MANUFACTURE BY METAL ORGANIC CHEMICAL VAPOR DEPOSITION
}

\section{TOPICAL REPORT}

James N. Chapman

University of Tennessee Space Institute

B. H. Goethert Parkway

Tullahoma, TN 37388-9700

July 1999

${ }^{*}$ This work was performed under Contract No. DE-AC22-95PC95231 


\section{DISCLAIMER}

This report was prepared as an account of work sponsored by an agency of the United States Government. Neither the United States Government, nor any agency thereof, nor any of their employees, makes any warranty, express or implied, or assumes any legal liability or responsibility for the accuracy, completeness, or usefulness of any information, apparatus, product, or process disclosed, or represents that its use would not infringe privately owned rights. Reference herein to any specific commercial product, process, or service by trade name, trademark, manufacturer, or otherwise does not necessarily constitute or imply its endorsement, recommendation, or favoring by the United States Government or any agency thereof. The views and opinions of authors expressed herein do not necessarily state or reflect those of the United States Government or any agency thereof. 


\section{TABLE OF CONTENTS}

Section

$\underline{\text { Page }}$

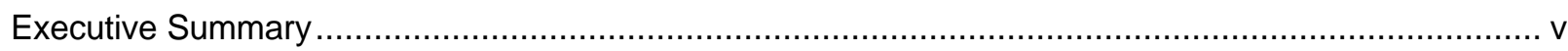

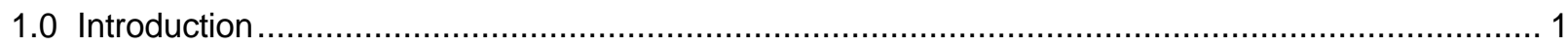

2.0 Description of the Production Facility and Assumptions Used ............................................. 1

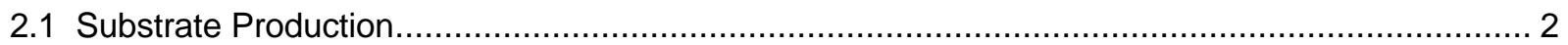

2.2 Application of the YBCO Superconductor by the MOVCD Process ........................................ 3

2.3 Post Deposition Oxidation/Annealing and Cool-Down Stage ................................................. 5

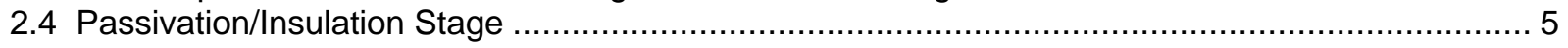

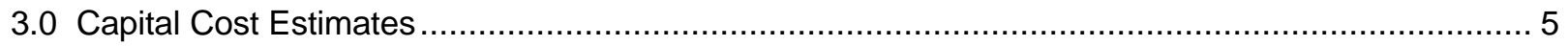

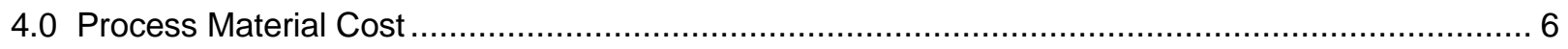

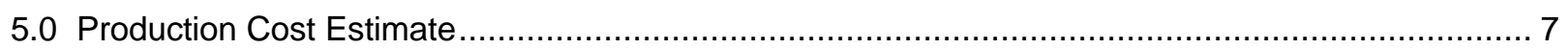

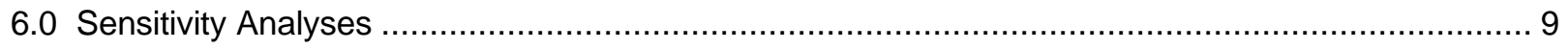

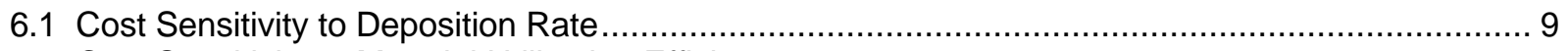

6.2 Cost Sensitivity to Material Utilization Efficiency ............................................................... 9

6.3 Cost Sensitivity to Metal Organic Chemical Precursor Cost ............................................... 10

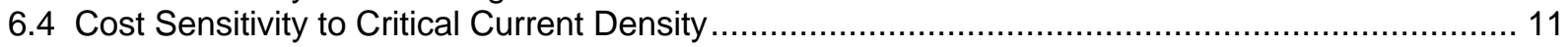

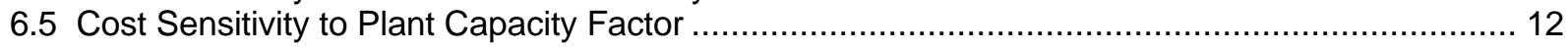

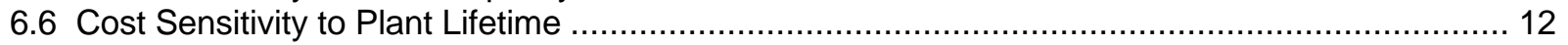

6.7 Cost Sensitivity to Superconductor Layer Thickness ........................................................ 13

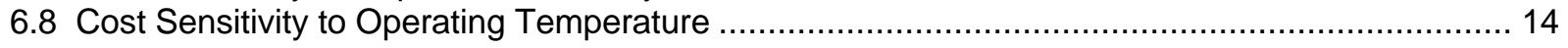

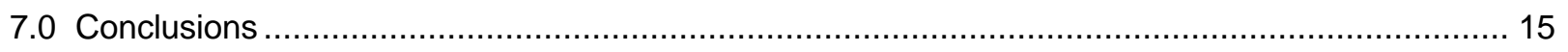

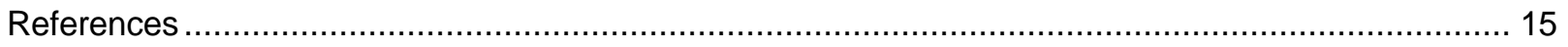


2.0-1 Assumed Conductor Configuration (Not to Scale) .............................................................. 2

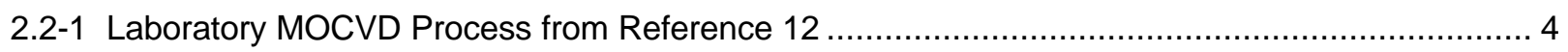

2.2-2 Assumed Concept for Commercial MOCVD Production..................................................... 4

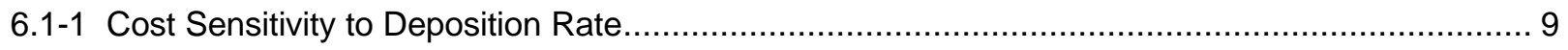

6.2-1 Cost Sensitivity to Material Utilization Efficiency ........................................................ 10

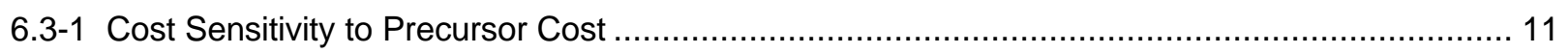

6.4-1 Cost Sensitivity to Critical Current Density................................................................... 11

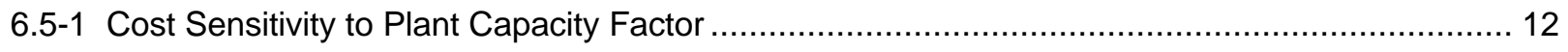

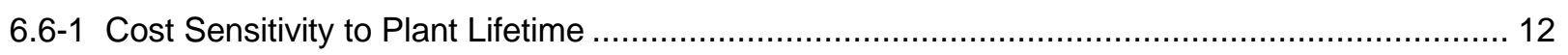

6.7-1 Geometric Fill Factor vs. Superconductor Thickness ................................................ 13

6.7-2 Cost Sensitivity to Superconductor Layer Thickness.................................................. 13

6.8-1 Cost Sensitivity to Operating Temperature, $\mathrm{B}=0$ Case ................................................... 14

6.8-2 Cost Sensitivity to Operating Temperature, $B=5$ T Case ................................................... 15 


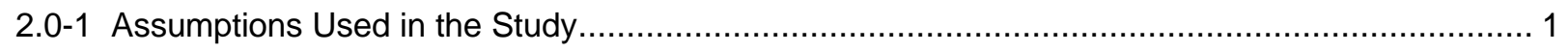

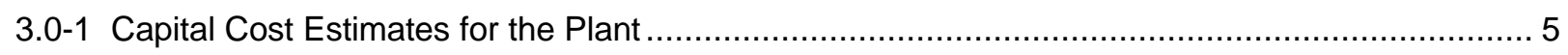

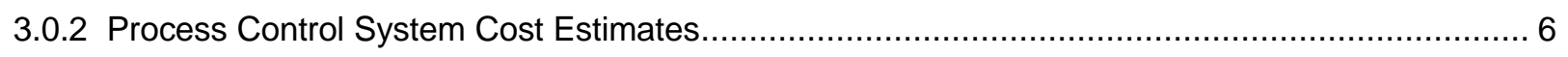

4.0-1 Consumable Cost for Assumed Production ............................................................... 7

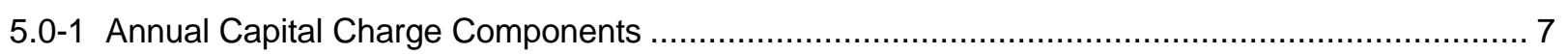

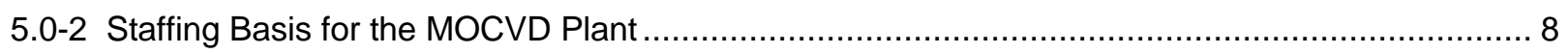

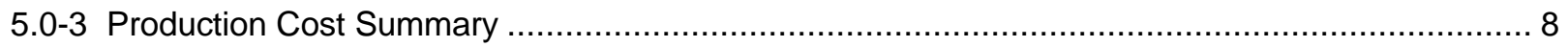




\section{EXECUTIVE SUMMARY}

The purpose of this report is to calculate the cost of producing high temperature superconducting wire by the Metal Organic Chemical Vapor Deposition (MOCVD) process. The technology status is reviewed from the literature and a plant conceptual design is assumed for the cost calculation. The critical issues discussed are the high cost of the metal organic precursors, the material utilization efficiency and the capability of the final product as measured by the critical current density achieved. Capital, operating and material costs are estimated and summed as the basis for calculating the cost per unit length of wire. Sensitivity analyses of key assumptions are examined to determine their effects on the final wire cost. Additionally, the cost of wire on the basis of cost per kiloampere per meter is calculated for operation at lower temperatures than the liquid nitrogen boiling temperature. It is concluded that this process should not be ruled out on the basis of high cost of precursors alone. 


\subsection{Introduction}

Recent results from small laboratory samples have shown performance of high temperature superconductors made by epitaxial deposition of thin films to be approaching the performance needed for commercial production and application ${ }^{1,2}$. One of the biggest hurdles to widespread application of these wires is developing a manufacturing process that will produce them in long lengths and at prices competitive to copper for applications such as motors, generators, transformers and power transmission cables.

UTSI has completed a study of known processes for manufacturing such thin film high temperature superconducting wire (dubbed coated conductors) ${ }^{3}$. This study compared the characteristics of manufacturing processes and concluded that Metal Organics Deposition (MOD), Sol-Gel, Metal Organic Chemical Vapor Deposition (MOCVD), electron beam and Pulsed Laser Deposition (PLD) are the most promising processes. A Cost/Performance Study ${ }^{4}$ has been published that explores the factors affecting the economic viability of production of coated conductors by the electron beam and PLD processes. The purpose of this report is to investigate the economic viability of the MOCVD Process. Applicable portions of the earlier report ${ }^{4}$ are used in this study.

The Draft Research and Development Roadmap to Achieve Electrical Wire Advancements from Superconducting Coatings ${ }^{5}$ establishes a cost goal of $\$ 10.00 / \mathrm{kAmp}-\mathrm{m}$ for the wire when it is commercialized. This goal was established as being necessary for the superconducting wire to replace copper in large scale applications in the electrical utility industry. There are other applications that may justify a higher price, such as aircraft and spacecraft systems, where weight and/or space savings may be more important ${ }^{6}$.

\subsection{Description of the Production Facility and Assumptions Used}

It is the intent of this study to compare costs in an era in which the coated conductor is fully commercial. An annual production rate of 18,000,000 meters/year was chosen as the production target. Many assumptions were chosen based on the "Research and Development Roadmap to Achieve Electrical Wire Advancements from Superconducting Coatings"5. Some key assumptions are listed in Table 2-1. The effects of key assumptions are evaluated by sensitivity analyses in the study.

Table 2-1 Assumptions Used in the Study

\begin{tabular}{|l|l|}
\hline $\begin{array}{l}\text { Critical Current Density in the } \\
\text { Superconductor: }\end{array}$ & $\begin{array}{l}10^{6} \mathrm{~A} / \mathrm{cm}^{2} \text { for self field, } \\
10^{5} \mathrm{~A} / \mathrm{cm}^{2} \text { for } 5 \text { Tesla } \perp \\
\text { field }\end{array}$ \\
\hline Plant Capacity: & $18,000 \mathrm{~km} / \mathrm{yr}$ \\
\hline Plant Lifetime: & 10 Years \\
\hline Wire Composition: & Shown in Figure 2-1 \\
\hline Annual Capital Charge: & $\begin{array}{l}24.7 \%, \text { Including } 10 \% \\
\text { Depreciation }\end{array}$ \\
\hline Capacity Factor: & $65 \%$ \\
\hline Deposition Rate: & $2000 \AA / \mathrm{min}$ \\
\hline
\end{tabular}




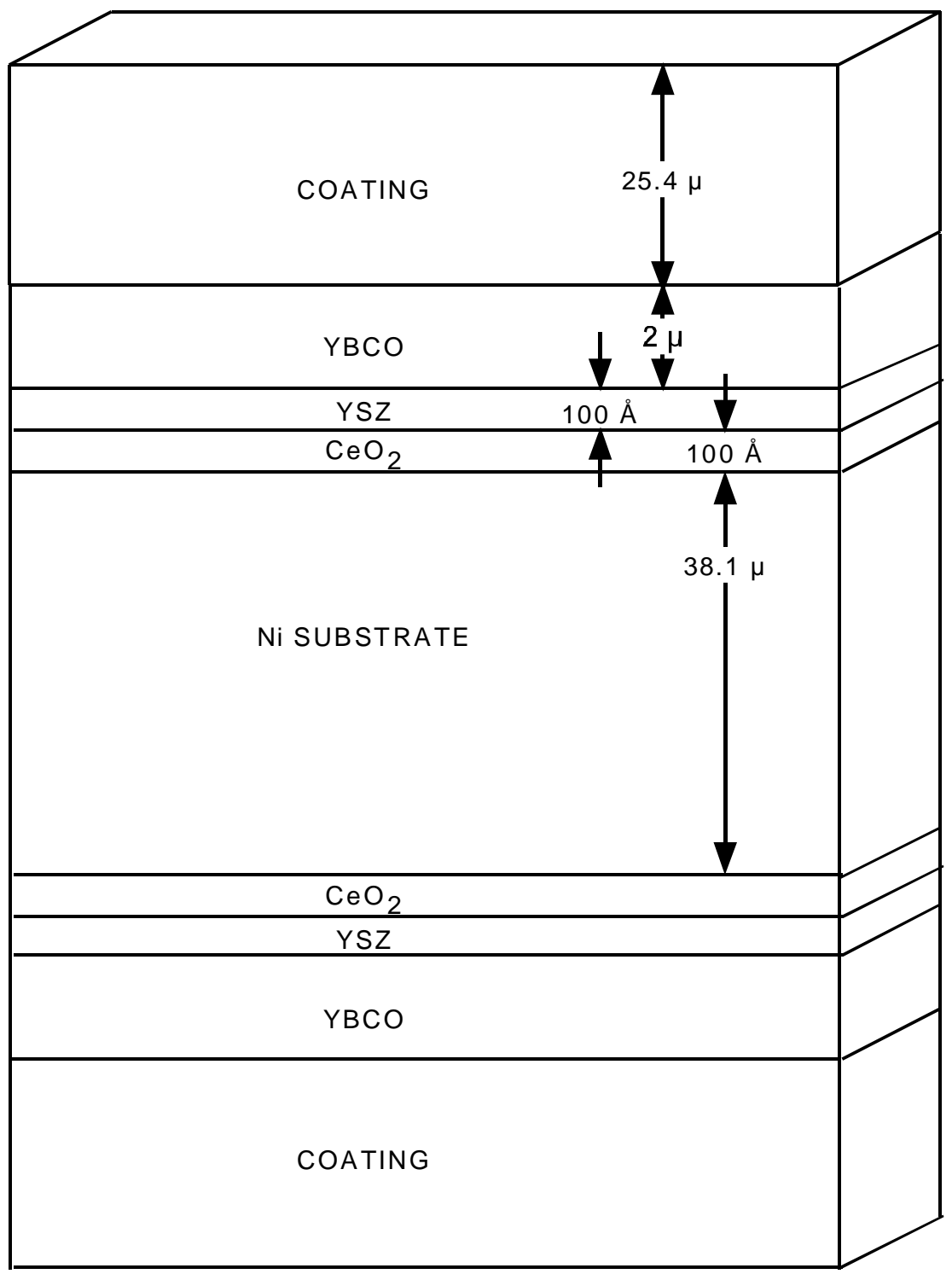

Figure 2.0-1 Assumed Conductor Configuration (Not to scale)

\subsection{Substrate Production}

The plant choices for substrate and buffer layer are based on rolled nickel strip with two buffer layers applied by electron beam web coaters as used in the previous study. The initial step includes a rolling mill to texture high purity nickel. The mill assumed has 5 stages, with $25 \%$ reduction at each stage. The mill is used for two passes in tandem to reduce the nickel strip $95 \%$ from its initial thickness of $762 \mu$ (30 mils) to $38.1 \mu$ (1.5 mils). The rolling mill includes a control system that measures the surface smoothness and thickness and implements control actions to keep the mill in tolerance. The rolled strip is stored on reels and batch annealed in an atmosphere of $96 \%$ argon and $4 \%$ hydrogen.

The textured nickel strip then is processed through two electron beam web coaters. The first applies a cerium oxide layer $100 \AA$ thick. (Note that the conductor architecture is still under development ${ }^{7}$ and it is unlikely that the assumed configuration will be the final choice. However, the cost impact is believed to be realistic.) The second web coater applies a yttrium stabilized zirconia (YSZ) layer $100 \AA$ thick. The web coaters are near commercial products with instrumentation added to evaluate the quality 
of the crystalline layers being deposited to assure layers adequate for epitaxial application of successive layers.

\subsection{Application of the YBCO Superconductor by the MOVCD Process}

The MOCVD process depends upon using metal organic compounds of the desired Yttrium, Barium and Copper precursors. The compounds are vaporized and transported to the substrate by a carrier gas of nitrogen or argon. The substrate is heated so that the vaporized precursors are thermally decomposed in the vicinity of the hot surface. The process depends upon the Yttrium, Barium and Copper being freed from the metal organic portion of the compounds and deposited on the substrate. The resulting YBCO will grow in the correct crystalline structure if conditions and oxidation levels are favorable. The metal organic portion of the molecules, together with the carrier gas and unused oxidant are pumped out of the chamber for disposal or recycling. Formation of the desired YBCO compound also depends critically on the control of the stoichiometry of the arriving precursors. Options to achieve accurate control of stoichiometry have included: i) mixing the precursor powders in the desired ratio before vaporizing them, ii) dissolving the precursors in liquid because liquid flows can be controlled more closely $^{8}$ and iii) accurate measurement of the concentration of $\mathrm{Y}, \mathrm{Ba}$ and $\mathrm{Cu}$ in the close vicinity of the substrate so that vaporization and transport rates can be controlled individually. Difficulties are encountered with i) because of the different vaporization temperatures of the precursors and residues left by some, especially the Barium THD. The liquid process adds to the cost and volume of the precursors, which are already at least marginally too high for commercial use and does not solve the residue problem. What is assumed in this study is iii), with measurement of the precursor concentration by absorption spectroscopy ${ }^{9}$ and automatic control by temperature of the oven and the flow rate of transport gases and residue removal from the individual vaporization chambers as needed.

The compounds used to date have been principally $\mathrm{Y}(\mathrm{THD})_{3}, \mathrm{Ba}(\mathrm{THD})_{2}$, and $\mathrm{Cu}(\mathrm{THD})_{2}$, where THD stands for 2,2,6,6-tetramethyl-3,5-heptanedionate. These compounds are also called dipivaloylmethane (DPM), interchangeably with THD. Other compounds are possible that will function in the MOCVD process but no more desirable ones have been discovered ${ }^{10}$. The problems of economic viability for this process start with high cost for the metal organic precursors and the fact that they contain only $14 \%, 27 \%$ and $15 \%$ of the desired elements, $\mathrm{Y}, \mathrm{Ba}$ and $\mathrm{Cu}$, respectively. Because of this, it is apparent that this process can be competitive only if a high material utilization efficiency can be achieved.

Figure 2.2-1 shows a schematic of a laboratory MOCVD apparatus as used in Reference 12. To achieve high material utilization efficiency, all pipes and walls should be kept at a temperature lower than the lowest decomposition temperature but higher than the highest solidification temperature. It is also clear that the geometry shown in the figure would result in a very small fraction of the precursors being close enough to the heated substrate to decompose and an even smaller fraction would deposit on the substrate. This may be acceptable in the laboratory where small samples are desired but for commercial production, engineering needs to be applied to improve the material utilization. The chamber should have an aerodynamic shape so that nearly all the gas contacts the heated substrate and so that the velocity of the transport gas/vaporized precursor mixture is very low in the vicinity of the heated substrate to maximize the amount of the precursor that is thermally decomposed due to heat transfer from the heated substrate.

Another obvious design parameter is that the deposition cannot take place on a large area that is subsequently sliced into the tape width desired. Since the precursors are transported to the substrate by a carrier gas, there would be large variations in the deposition thickness as this gas, and those from the THD portion of the metal organic compound, must flow around the edges of the substrate to be pumped out of the chamber. A suggested conceptual arrangement for the substrate in the chamber is shown in Figure 2.2-2. The angle of inclination of the substrate with respect to the chamber centerline is assumed to be $45^{\circ}$ for the quantitative work in this study. The tape width is $1 \mathrm{~cm}$. Two-sided deposition is achieved by inverting the tape internal to the chamber.

MOCVD deposition rates have been reported in the literature from 333 to $1800 \AA / \mathrm{min}$. The most relevant reference as to permissible deposition rates seems to be Chou ${ }^{11}$, who compared deposition at 
$1400 \AA /$ min with $1800 \AA / m i n$ and found no degradation at the higher rate. In view of this data, a base case deposition rate is chosen as $2,000 \AA /$ min for this study. For manufacture of $18,000,000$ meters/year at a base case capacity factor of 0.65 , a deposition area of $10.5 \mathrm{~m}^{2}$ is required. For double-sided application, twice the deposition area or $21 \mathrm{~m}^{2}$ would be required. For this process, there seems to be no reason not to use a large single chamber rather than several smaller ones. The use of a 45 degree tape inclination will permit the reduction in the dimension perpendicular to the tape travel to a factor of 0.7 so the dimensions of the deposition area need to be $3.87 \mathrm{~m} \times 3.87 \mathrm{~m}$. Based upon scaling the costs used in the previous study ${ }^{4}$ by the 0.6 exponent method, a cost estimate for the chamber itself is $\$ 3.83$ million. Multiple furnaces for vaporizing the precursors are provided, with valves so that a chamber can be taken off line and recharged without interrupting the process. For cost estimates three furnaces each were used for copper and yttrium and four for the barium. All the lines and surfaces are heated to control the temperature to between the highest metal organic vaporization temperature and the lowest decomposition temperature. Radiant heaters are provided to heat the face of the substrate to the desired temperature, up to $850^{\circ} \mathrm{C}$.

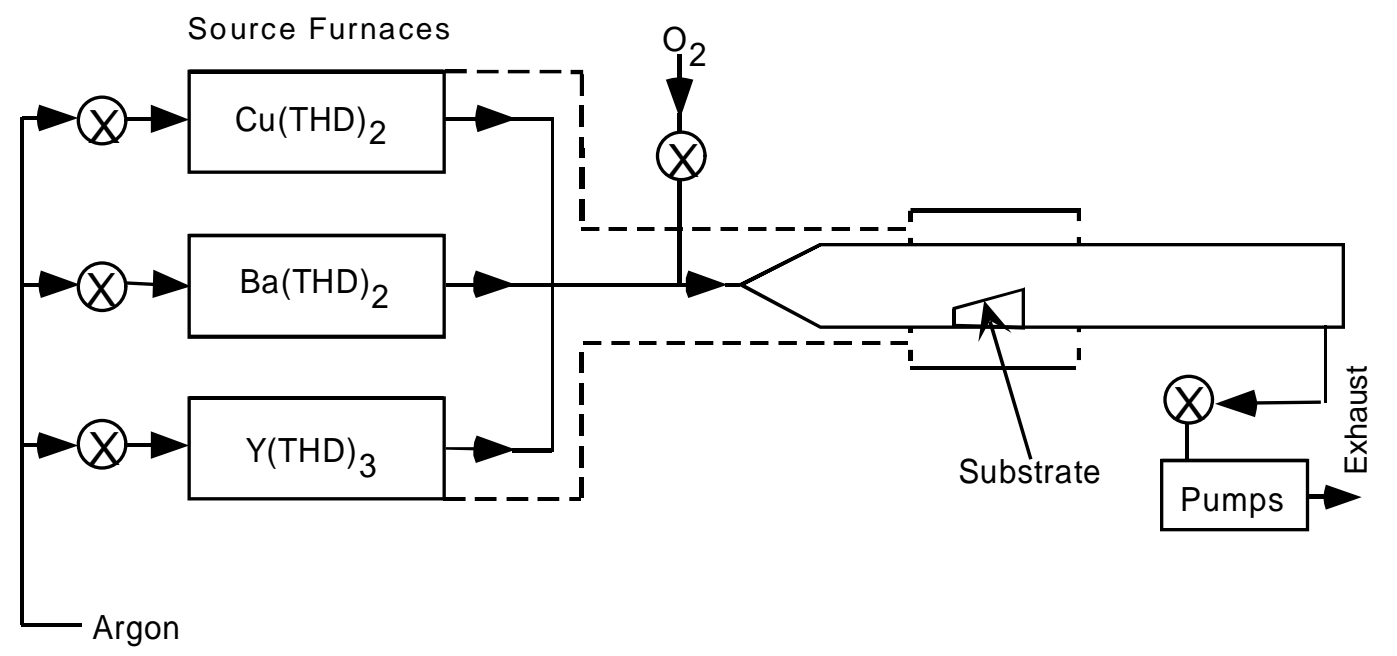

Figure 2.2.1 Laboratory MOCVD Process from Reference 12

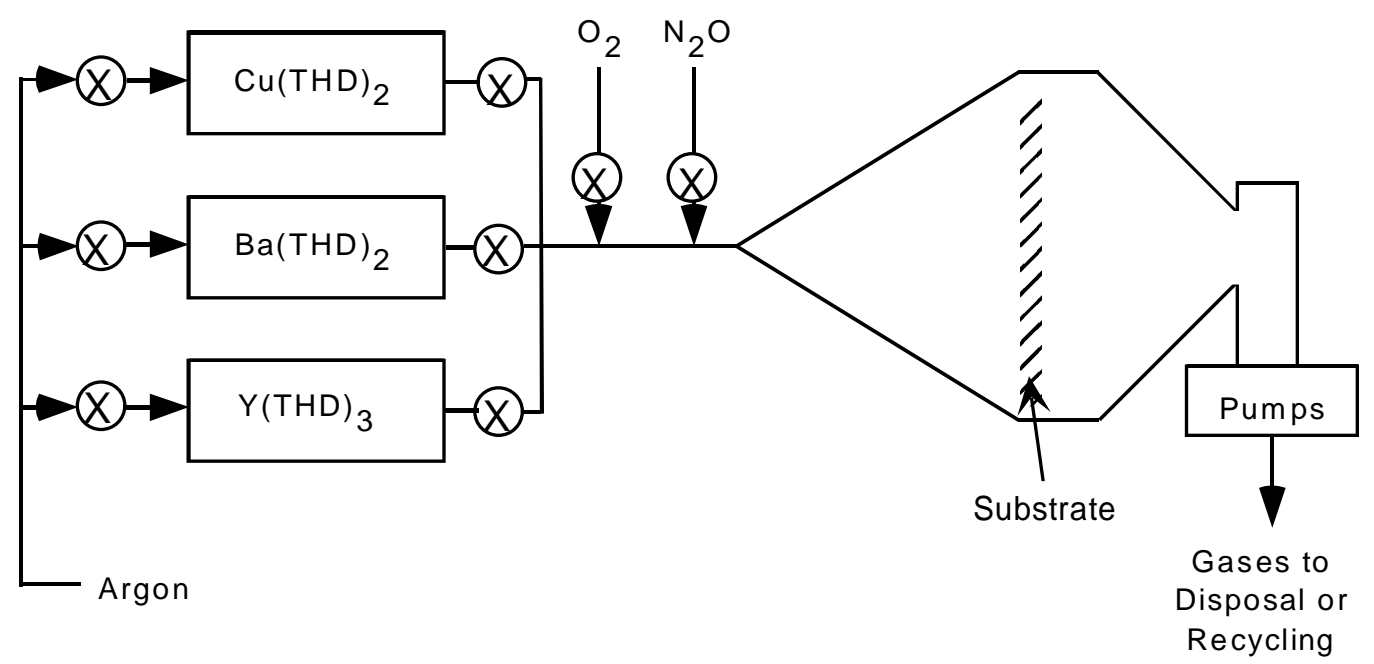

Figure 2.2-2 Assumed Concept for Commercial MOCVD Production

The control system includes an absorption spectrometer to measure the concentration of precursors and automatically control them by adjusting the furnace temperatures and transport gas flows. 
Nitrous oxide, $\mathrm{N}_{2} \mathrm{O}$, and oxygen, $\mathrm{O}_{2}$, are added to the chamber to get in situ reaction to form the desired YBCO compound to the extent possible. However, post processing is provided to enhance the performance.

\subsection{Post Deposition Oxidation/Annealing and Cool-Down Stage}

High quality YBCO films with high Tc and Jc values can be obtained by the MOCVD process, however, low temperature annealing for a longer time in an oxygen atmosphere improves the electrical properties of the film ${ }^{12}$. The reels of superconductor are removed from the MOCVD chamber periodically and transferred to the oxidation /annealing furnace where they are reheated and cooled in a prescribed time/temperature profile in the presence of oxygen.

\subsection{Passivation/Insulation Stage}

It is necessary to provide a layer to inert the superconductor tape from environment in which it will be used and to provide electrical insulation from ground or other electrical potentials. Very little work has been done on optimizing this layer for thin film superconductors. It is likely that the optimum layer to meet the requirement will depend upon the application for the superconductor. For this study, it has been assumed that the wire is insulated in a manner similar to current copper magnet wire. The capital costs include equipment to dip and dry, patterned after enamel application to copper wires used for motor windings. The material cost is considered negligible. As this requirement is developed in more detail, costs may need to be added to perform this function.

\subsection{Capital Cost Estimates}

The estimate of capital cost for the plant described is tabulated in Table 3.0-1. In this section, the source and logic for these cost estimates are discussed.

Table 3.0-1 Capital Cost Estimates for the Plant

\begin{tabular}{|l|r|}
\hline \multicolumn{1}{|c|}{ Equipment Category } & \multicolumn{1}{c|}{ Cost $\$$} \\
\hline Rolling Mill & 150,000 \\
\hline Heat Treatment Facility & 443,000 \\
\hline E-beam Web Coaters & $4,000,000$ \\
\hline MOCVD Chamber & $3,830,000$ \\
\hline Vacuum Pumps & 392,000 \\
\hline MOCVD Furnaces & 200,000 \\
\hline MOCVD Gas Facilities & 151,000 \\
\hline Final Heat Treatment System & 443,000 \\
\hline Environmental Treatment & 250,000 \\
\hline Passivation/Insulation & $1,000,000$ \\
\hline Tape Handling System & $1,000,000$ \\
\hline Control Systems & $5,709,000$ \\
\hline Laboratory/QA Test Facility & $1,500,000$ \\
\hline Site \& Development & 550,000 \\
\hline Elect. Substations & $1,000,000$ \\
\hline Buildings & $3,720,000$ \\
\hline Sub-total & $24,338,000$ \\
\hline AE Fee @ 15\% & $3,650,700$ \\
\hline Sub-total & $27,988,700$ \\
\hline Contingency @ 20\% & $5,597,740$ \\
\hline Total Capital Cost & $33,586,440$ \\
\hline
\end{tabular}


The rolling mill estimate is from a previous study ${ }^{4}$ except that it has been revised to reflect that it is for a five-stand mill ${ }^{13}$ and will be used to roll the nickel substrate twice. Each stage will reduce the substrate $25 \%$ or $95 \%$ overall. The estimate is for operation in air. The mill can be provided to work in inert gas if required, but at additional cost, but is not believed necessary since the annealing process is done in a reducing atmosphere. The annealing furnace and electron beam web coaters cost estimates are likewise derived from the previous study.

The environmental control system will have to process the solid $\mathrm{Y}, \mathrm{Ba}$ and $\mathrm{Cu}$ particles which are decomposed but not deposited on the substrate, the $\mathrm{Y}, \mathrm{Ba}$ and $\mathrm{Cu}-\mathrm{THD}$ compounds that were not thermally decomposed and the other exhaust gases pumped from the MOCVD deposition chamber. There will be exhaust from the annealing furnace (argon and hydrogen) and the heat treatment furnace (oxygen) but these processes are batch and quantities very small compared to the deposition chamber flow which is estimated at $4.6 \mathrm{lbm} / \mathrm{min}$. This exhaust is estimated to contain $3.66 \mathrm{lbm} / \mathrm{min}$ argon, 0.61 $\mathrm{lbm} / \mathrm{min}$ of nitrogen oxides, $0.26 \mathrm{lbm} / \mathrm{min}$ of oxygen and $0.08 \mathrm{lbm} / \mathrm{min}$ of $\mathrm{CO}$ and $\mathrm{CO}_{2}$ from the THD portions of the precursor compounds. Thus, it will likely require nitrogen oxide control and an air quality permit to exhaust to the atmosphere. The costs shown are based on cooling and filtering initially to collect any particulate, then a small natural gas augmented flare stack to oxidize the small amounts of hydrogen and carbon monoxide plus a selective catalytic reduction (SCR) system to remove $\mathrm{NO}_{\mathrm{x}}$. Costs are derived from scaling costs from reference 14. In view of the large concentration of argon in the exhaust (estimated 79\%), a cryogenic separation and recycling system should be investigated in a more detailed design.

The passivation/insulation system is largely undetermined. The capital cost included represents a rough engineering estimate of the cost of a 'dip and dry' system similar to that used on copper magnet wire. The tape handling system is likewise not a refined cost estimate but a rough estimate. Handling this thin tape reliably is an important issue for the success of the plant.

The process control system costs are a combination of engineering estimates and values derived from references. Table 3.0-2 lists the components of this estimate.

Table 3.0-2 Process Control System Cost Estimates

\begin{tabular}{|l|r|}
\hline Rolling and Annealing & $\$ 109,000$ \\
\hline Crystal Quality, MOCVD Process & $\$ 1,000,000$ \\
\hline Stoichiometry in MOCVD Process & $\$ 1,000,000$ \\
\hline Overall Process Control & $\$ 3,600,000$ \\
\hline Total & $\$ 5,709,000$ \\
\hline
\end{tabular}

The laboratory and quality assurance costs include general-purpose laboratory equipment including $x$-ray diffraction, scanning electron microscope, thermogravimetric analyzer, superconductivity test set and atomic force microscopy equipment. The major QA expense is for a capability to final test a reel of cable at liquid nitrogen temperature for critical current.

The site is 10 acres of land with driveways, parking areas and lighting. The metal building is sized at $100,000 \mathrm{ft}^{2}$ and estimated ${ }^{4}$ at $\$ 37.20 / \mathrm{ft}^{2}$. The size of the substation, $25 \mathrm{MWe}$ and the costs are engineering estimates.

\subsection{Process Material Costs}

As previously noted, one of the big obstacles to economic commercial production of coated conductors by the MOCVD process is the high cost of the metal organic precursors. Furthermore, the desired content of $\mathrm{Y}, \mathrm{Ba}$ and $\mathrm{Cu}$ is only $14 \%, 27 \%$ and $15 \%$, respectively. If one takes the current catalog prices for these chemicals and scale them by the method given in reference 3 , the projected price for each chemical is around $\$ 5,000 / \mathrm{kg}$. Several of the companies that sell these chemicals is small lots were requested to provide an estimate of what the price might be in quantities of several thousand kilograms 
per year. Only INORGTECH replied ${ }^{15}$ and indicated with process improvements and economies of scale, they did not believe the price would be less than $\$ 1000 / \mathrm{kg}$. That number has been used in computing the base case cost of the metalorganic compounds.

In view of this high price of the precursors, the utilization efficiency of these compounds is a critical issue. The loss mechanisms are material that is not vaporized and material that escapes the chamber with the transport gases, either as the metal organic compound that is not decomposed or as $\mathrm{Y}$, $\mathrm{Ba}$ or $\mathrm{Cu}$ after decomposition. There should be no loss to the pipe and chamber walls if they are kept above the vaporization temperatures for all the compounds and below the decomposition temperatures. Thermogravimetric analyses (TGA) in the UTSI laboratory found residues in the chamber that did not vaporize of $6-7 \%$ for the $\mathrm{Ba}(\mathrm{THD})_{2}, 1-4 \%$ for the $\mathrm{Y}(\mathrm{THD})_{3}$ and none for the $\mathrm{Cu}(\mathrm{THD})_{2}$. It is difficult to estimate the amount that may blow by the substrate. If the system is optimized for both uniform, low speed gas flow in the chamber and the geometry of the deposition zone that maximizes deposition, it appears that a high utilization can be achieved. Based on this reasoning, a utilization rate of $85 \%$ is chosen for the base case. Of course, this will be varied in a sensitivity analysis.

The nickel, cerium and YSZ prices are taken from the previous study ${ }^{4}$. Costs for the argon, hydrogen, oxygen and nitrous oxide were provided by BOC Gases ${ }^{16}$.

The base case consumable costs are shown in Table 4.0-1.

Table 4.0-1 Consumable Cost for Assumed Production

\begin{tabular}{|c|c|c|c|c|}
\hline Material & \multicolumn{2}{|c|}{ Unit Cost/kg } & \multicolumn{2}{|r|}{ Annual Cost } \\
\hline Nickel & $\$$ & 38.27 & $\$$ & $2,330,000.00$ \\
\hline Yttrium THD & $\$$ & $1,000.00$ & $\$$ & $3,470,000.00$ \\
\hline Barium THD & $\$$ & $1,000.00$ & $\$$ & $5,447,000.00$ \\
\hline Copper THD & $\$$ & $1,000.00$ & $\$$ & $6,970,000.00$ \\
\hline Cerium & $\$$ & 394.00 & $\$$ & $79,082.00$ \\
\hline YSZ & $\$$ & $1,298.00$ & $\$$ & $246,865.00$ \\
\hline Argon & $\$$ & 0.08 & $\$$ & $228,000.00$ \\
\hline Nitrous Oxide & $\$$ & 0.15 & $\$$ & $68,000.00$ \\
\hline Hydrogen & $\$$ & 0.04 & $\$$ & $91,200.00$ \\
\hline Oxygen & $\$$ & 0.05 & $\$$ & $5,100.00$ \\
\hline Total Materials, $\$ / y r$ & & & $\$$ & $18,935,247.00$ \\
\hline
\end{tabular}

\subsection{Production Cost Estimate}

The capital costs as shown in Table 3.0-1 result in annualized capital costs that include depreciation of the plant and equipment, interest on capital, taxes and working capital. Table 5.0-1 shows the factors used to derive the $24.7 \%$ annual cost rate for the base case of this study.

Table 5.0-1 Annual Capital Charge Components

\begin{tabular}{|l|c|}
\hline Cost of Money & $7.5 \%$ \\
\hline Income Taxes & $4.1 \%$ \\
\hline Depreciation, 10 years s/l & $10.0 \%$ \\
\hline Other Taxes & $2.8 \%$ \\
\hline Working Capital & $0.2 \%$ \\
\hline Insurance & $0.1 \%$ \\
\hline
\end{tabular}

The labor costs are based on the staffing shown in Table 5.0-2 and an average labor rate of $\$ 25.00 /$ hour plus $26 \%$ for fringe benefits. 
Table 5.0-2 Staffing Basis for the MOCVD Plant

\begin{tabular}{|c|c|}
\hline Function & Personnel \\
\hline Rolling and Annealing & 2/shift \\
\hline Web Coating Buffer Layers & 4/shift \\
\hline YBCO Application by MOCVD & 4/shift \\
\hline Environmental Cleanup & 2/shift \\
\hline Plant Maintenance & 2/shift \\
\hline Janitorial & 2/shift \\
\hline Shift Manager & 1/shift \\
\hline QA Engineer & 1/shift \\
\hline Engineer & 1/shift \\
\hline Shipping, Receiving, Materials Mgmt. & 2/shift \\
\hline Total & $21 /$ shift \\
\hline Total Shift Workers & 103 \\
\hline Secretary/Accountant & 2 \\
\hline Purchasing Personnel & 2 \\
\hline Chemist & 1 \\
\hline Plant Manager & 1 \\
\hline Total Labor & 109 \\
\hline
\end{tabular}

The production cost summary is shown in Table 5.0-3. An annual allowance of $10 \%$ of the total capital cost is included for maintenance of plant and equipment. The materials cost is as listed in Table 4.0-1. Electricity and other utility costs are based on an engineering estimate and an overall cost of electricity of $\$ 60.00 / \mathrm{MWh}$.

\section{Table 5.0-3 Production Cost Summary}

\begin{tabular}{|l|rr|}
\hline Materials Cost, \$/yr & $\$$ & $18,935,247.00$ \\
\hline Capital Charges @ 24.7\%, \$/yr & $\$$ & $8,295,851.00$ \\
\hline Maintenance @10\% of Capital, \$/yr & $\$$ & $3,358,644.00$ \\
\hline Labor, \$/year & $\$$ & $7,142,000.00$ \\
\hline Electricity, other utilities, \$/yr & $\$$ & $3,000,000.00$ \\
\hline Total Annual Cost, \$/yr & $\$$ & $40,731,742.00$ \\
\hline Annual Production, meters & $\$$ & $18,000,000.00$ \\
\hline Critical Current, Amperes & $\$$ & 400.00 \\
\hline Cost, \$/meter & $\$$ & 2.26 \\
\hline Cost, \$/Kiloampere meter & \\
\hline
\end{tabular}

*for $\mathrm{J}_{\mathrm{c}}=10^{6} \mathrm{~A} / \mathrm{cm}^{2}$

As shown, the base case production cost is $\$ 2.26 /$ meter. This translates to $\$ 5.66 / \mathrm{kA}-\mathrm{m}$ for a current density of $10^{6} \mathrm{~A} / \mathrm{cm}^{2}$ or $\$ 56.60 / \mathrm{kA}-\mathrm{m}$ if the current density is lower by a factor of 10 . This compares with the $\$ 4.28 / 42.75$ for the electron beam base case and $\$ 7.72 / 77.18 / \mathrm{kA}-\mathrm{m}$ for PLD from reference 4. This calculation would seem to indicate that the MOCVD process should not be ruled out on the basis of high material costs. It should be remembered that this result depends critically on the assumptions used, especially the cost of the metal organic precursors and the material utilization efficiency. These and other assumptions will be the subject of sensitivity analyses in the next section. 


\subsection{Sensitivity Analyses}

The purpose of this section is to examine the sensitivity of the result to some key assumptions. For illustrative purposes, these analyses use the $J_{c}=10^{6} \mathrm{~A} / \mathrm{cm}^{2}$ case, which is the goal for conductors in self field. Results can be adapted for other current densities by multiplying the cost by the ratio of critical current densities.

\subsection{Cost Sensitivity to Deposition Rate}

The base case deposition rate of $2000 \AA /$ min was assumed. If a lower rate is used, the principal cost impact will be increased size of the deposition chamber and increased cost of tape handling equipment. If a higher rate can be used, these costs will be reduced. It seems unlikely that the deposition rate will have to be lower to get good crystalline quality in view of the experimental work already in the literature. However, it is possible that the deposition rate may need to be lower to optimize the material utilization efficiency. Figure 6.1-1 shows the result of varying the deposition rate from 500 to $5000 \AA / \mathrm{min}$. The resulting cost variation is not critical to the economic viability of the plant because the annualized cost for the deposition chamber and tape handling equipment are not a large part of the production cost.

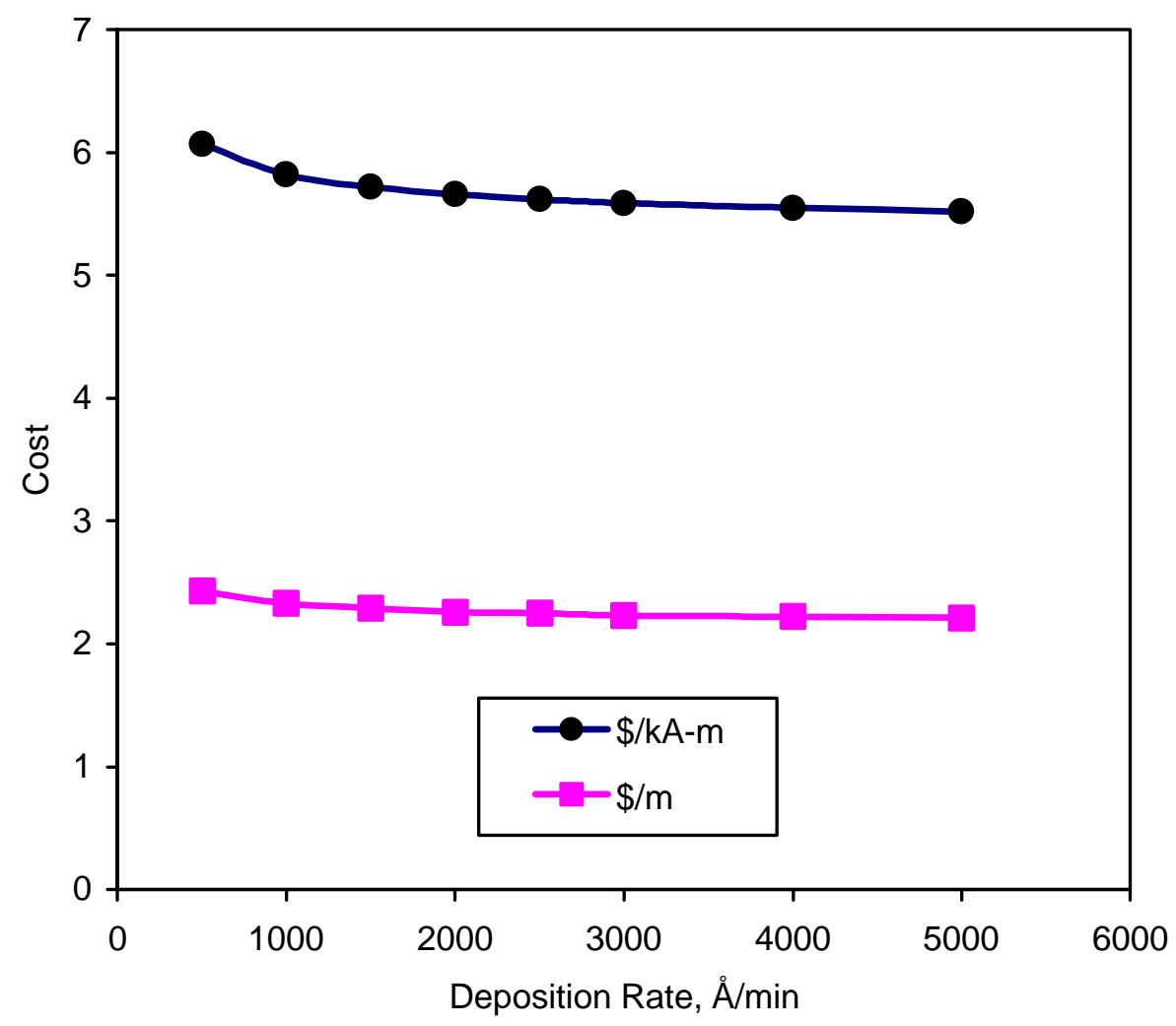

Figure 6.1-1 Cost Sensitivity to Deposition Rate

\subsection{Cost Sensitivity to Material Utilization Efficiency}

As previously mentioned, the precursor metal organic chemicals used in the MOCVD process are expensive. In the base case, the consumable materials cost is $46.5 \%$ of the total production cost. This compares with $26.1 \%$ for the electron beam process and $21.6 \%$ for PLD. Because of this, the material 
utilization efficiency is a critical issue. The effect of this utilization efficiency is shown in Figure 6.2-1. Note that for low efficiencies, such as the $15 \%$ sometimes attributed to all vapor processes, the cost of production is about $\$ 18$ for the $J_{c}=10^{6} \mathrm{a} / \mathrm{cm}^{2}$ case displayed or $\$ 180$ for the $J_{c}=10^{5} \mathrm{a} / \mathrm{cm}^{2}$ case. This illustrates why it is essential to improve the utilization efficiency if MOCVD is to be a candidate for large scale commercial production.

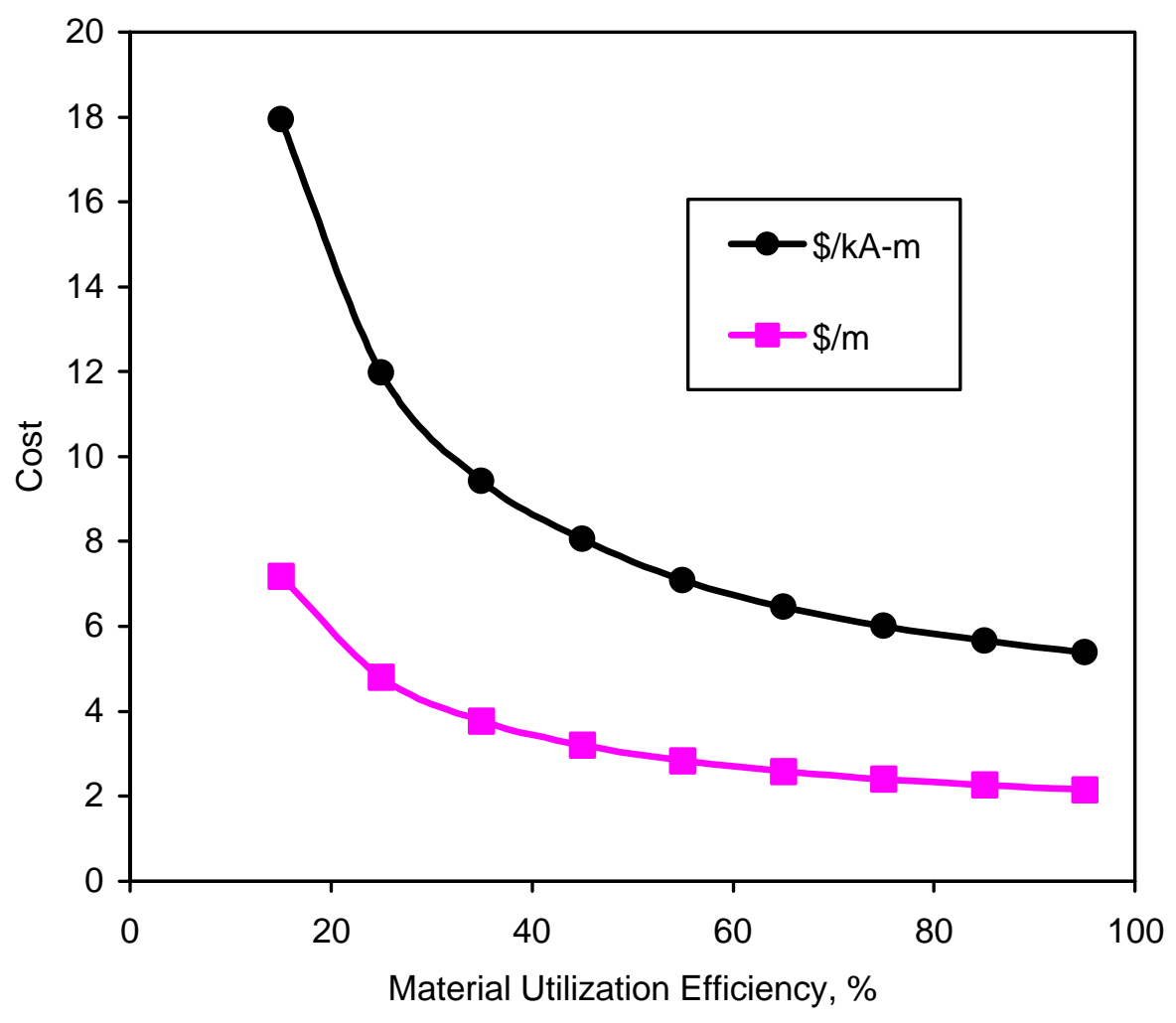

Figure 6.2-1 Cost Sensitivity to Material Utilization Efficiency

\subsection{Cost Sensitivity to Metal Organic Chemical Precursor Cost}

As previously noted, the current availability of the $\mathrm{Ba}, \mathrm{Y}$ and $\mathrm{Cu}$ THD compounds is limited to small quantities for laboratory use. An estimated cost can be obtained by scaling current prices by: ${ }^{3}$

$$
C=" R^{-\$}
$$

where $\mathrm{C}=$ cost in $\$ / \mathrm{kg}$

$$
\begin{aligned}
& \text { ", \$ are constants to be determined } \\
& R \text { = Quantity purchased. }
\end{aligned}
$$

For current catalog prices for small lots, the scaled cost is about $\$ 5,000 / \mathrm{kg}$. Also as previously noted, one company expressed the view that the cost might be reduced to around $\$ 1,000 / \mathrm{kg}$ in quantities of thousands of kilograms/year. That value was used in the base case of this study but the uncertainty indicates the need to examine the wire cost as a function of the precursor price. Figure 6.3-1 shows the wire production cost effect for precursor costs from 500-5,000 \$/kg. At the 5,000 \$/kg price, the wire cost 
is $\$ 14.48 / \mathrm{kA}-\mathrm{m}$ for the $\mathrm{J}_{C}=10^{6} \mathrm{~A} / \mathrm{cm}^{2}$ case displayed or $\$ 144.48$ for the $J_{C}=10^{5} \mathrm{~A} / \mathrm{cm}^{2}$, clearly out of reach for the goal of $\$ 10.00 / \mathrm{kA}-\mathrm{m}$.

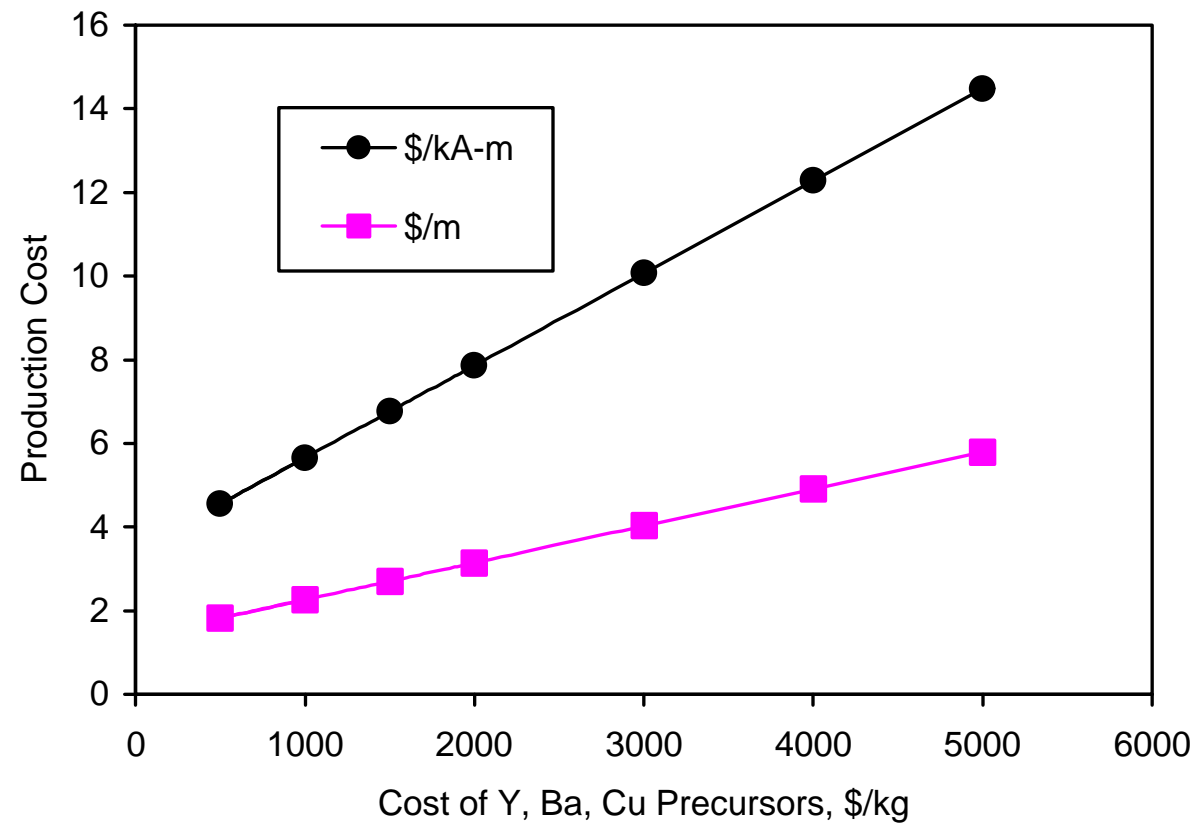

Figure 6.3-1 Cost Sensitivity to Precursor Cost

\subsection{Cost Sensitivity to Critical Current Density}

The critical current density achieved for the wire produced is the most critical issue as it determines the wire cross section required to carry a given current. Figure 6.4-1 shows the effect of current density on cost in $\$ / \mathrm{kA}-\mathrm{m}$. To meet the $10 \$ / \mathrm{kA}-\mathrm{m}$ would require a $\mathrm{J}_{\mathrm{c}}$ of $566 \mathrm{kA} / \mathrm{cm}^{2}$ at this production cost.

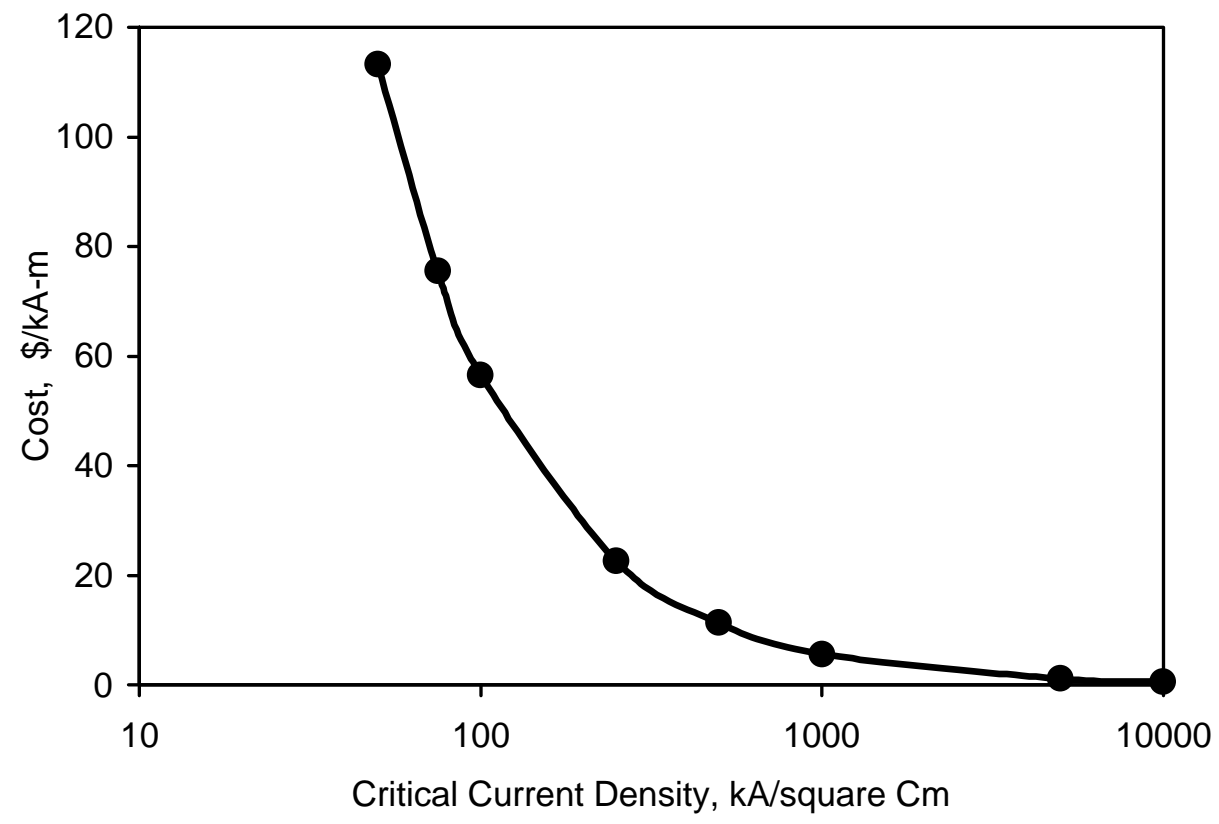

Figure 6.4-1 Cost Sensitivity to Critical Current Density 


\subsection{Cost Sensitivity to Plant Capacity Factor}

The plant capacity factor is the annual production divided by what the annual production would be if the plant operated continuously at rated throughput. It affects the cost of the wire produced because the fixed capital costs are spread over more production for higher capacity factors. The effect of this factor on wire production costs is shown in Figure 6.5-1.

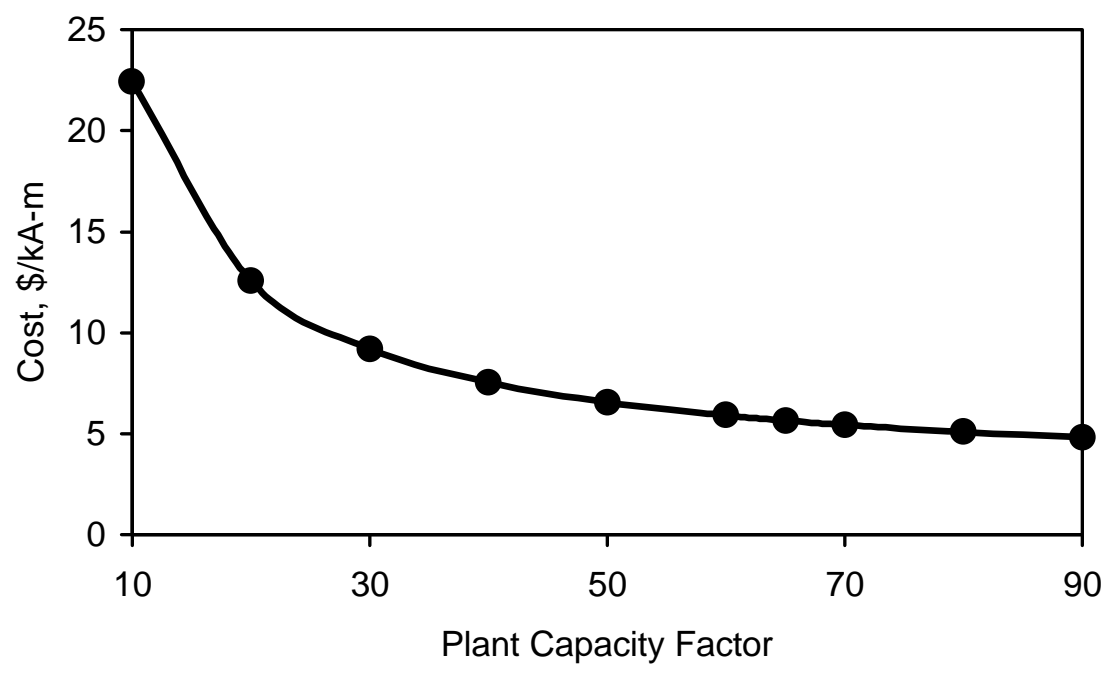

Figure 6.5-1 Cost Sensitivity to Plant Capacity Factor

\subsection{Cost Sensitivity to Plant Lifetime}

The plant lifetime affects the cost of production calculation by affecting the depreciation rate. In the base case, ten (10) years was chosen as the plant life. The effect of other plant lifetimes is shown in Figure 6.6-1.

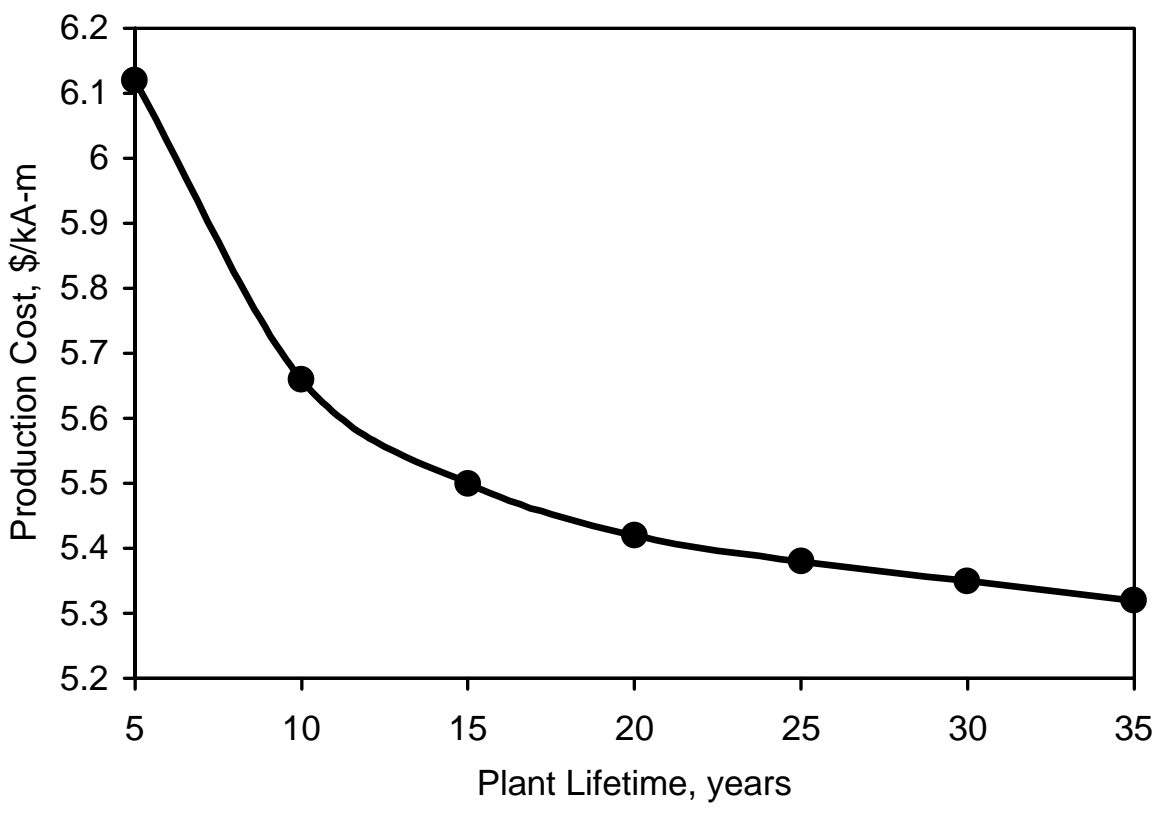

Figure 6.6-1 Cost Sensitivity to Plant Lifetime 


\subsection{Cost Sensitivity to Superconductor Layer Thickness}

The base case geometry chosen has only a two micron thick layer of superconductor on both sides of the wire. This was based on the lack of demonstrated capability to manufacture the wire with thicker layers and maintain the incremental current density found in thinner strips. The fill factor, as defined as the cross sectional area of the superconductor divided by the total cross section of the coated conductor, is only .043 for this base case. The fill factor for other thicknesses up to 10 : is shown in Figure 6.7-1.

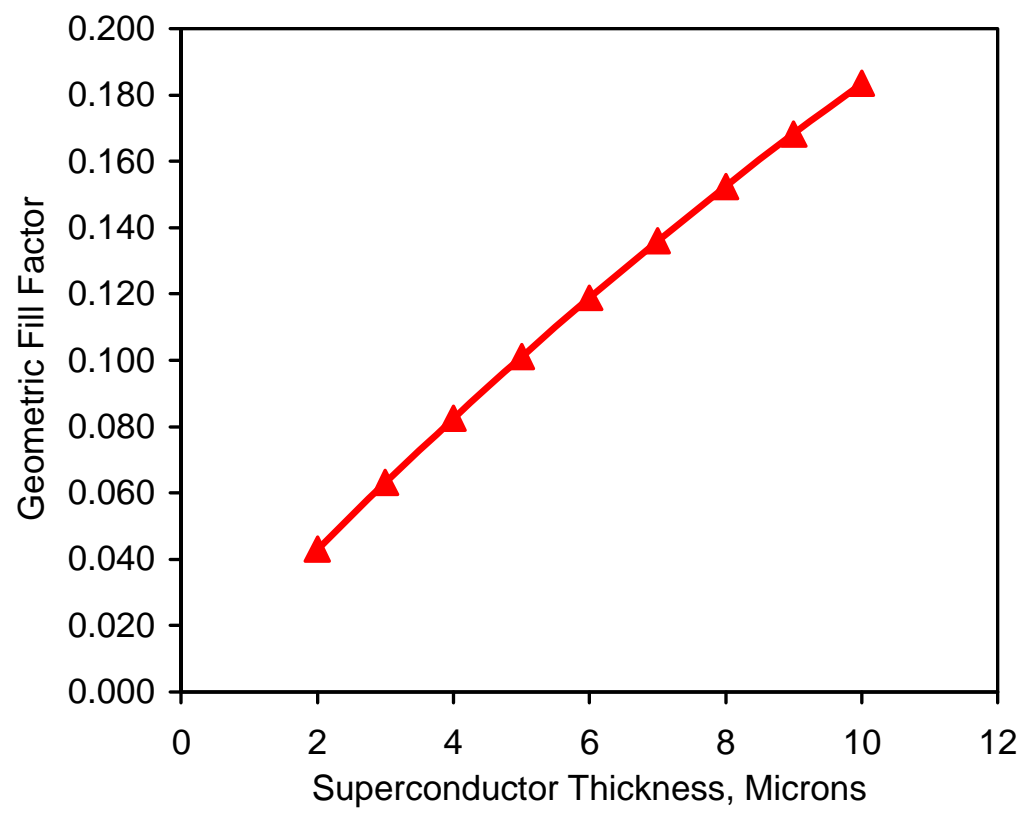

Figure 6.7-1 Geometric Fill Factor vs. Superconductor Thickness

The costs for other superconductor thicknesses are calculated by linearly scaling the precursor and deposition gas costs. The deposition chamber, vaporization furnaces, gas facilities and environmental systems are scaled by the 0.6 exponent method. The resulting cost implications are shown in Figure 6.72.

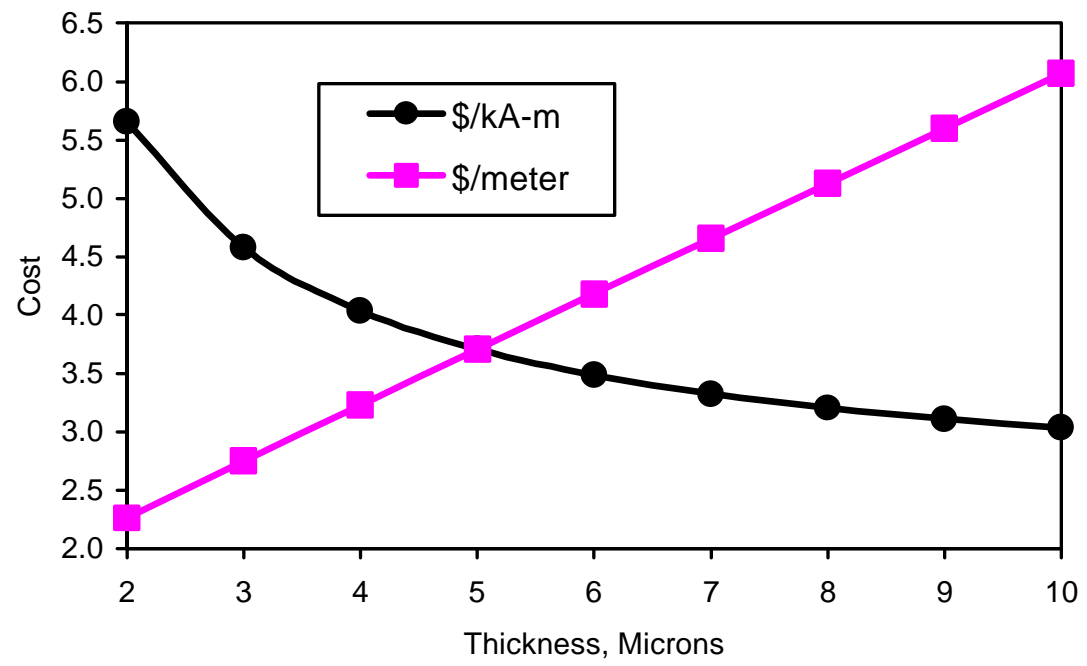

Figure 6.7-2 Cost Sensitivity to Superconductor Layer Thickness 
The cost in $\$ / m$ increases linearly with superconductor thickness but the cost in $\$ / k A-m$ decreases significantly.

\subsection{Cost Sensitivity to Operating Temperature}

The roadmap and its objectives were stated in terms of performance of the wires at liquid nitrogen temperatures, $77 \mathrm{~K}$ at sea level. Cooling to lower temperatures gives higher current densities but may result in a large increase in refrigeration capital and operating costs. However, a relevant issue may be how the wire cost stated in terms of $\$ / \mathrm{kA}-\mathrm{m}$ varies with operating temperature. For some applications, operations with a cryocooler at temperatures lower than $77 \mathrm{~K}$ may be feasible. The cost of manufacture of the wire will be the same, of course, but the performance will be enhanced at lower temperature. This will increase the cost of operation of the system, but decrease the cost for wire at the same current load.

The variation in $\mathrm{J}_{\mathrm{c}}$ as a function of operating temperature has been reported in many references. Figure 1.5 in Reference 5 is chosen to represent this variation. The original source for this figure is unknown, but is believed to be a consensus of measurements from several of the national laboratories.

For the base case conductor that meets the goals of $10^{6} \mathrm{Amps} / \mathrm{cm}^{2}$ at no field, the extrapolated current density and coated conductor cost in \$/kA-m are shown in Figure 6.8-1.

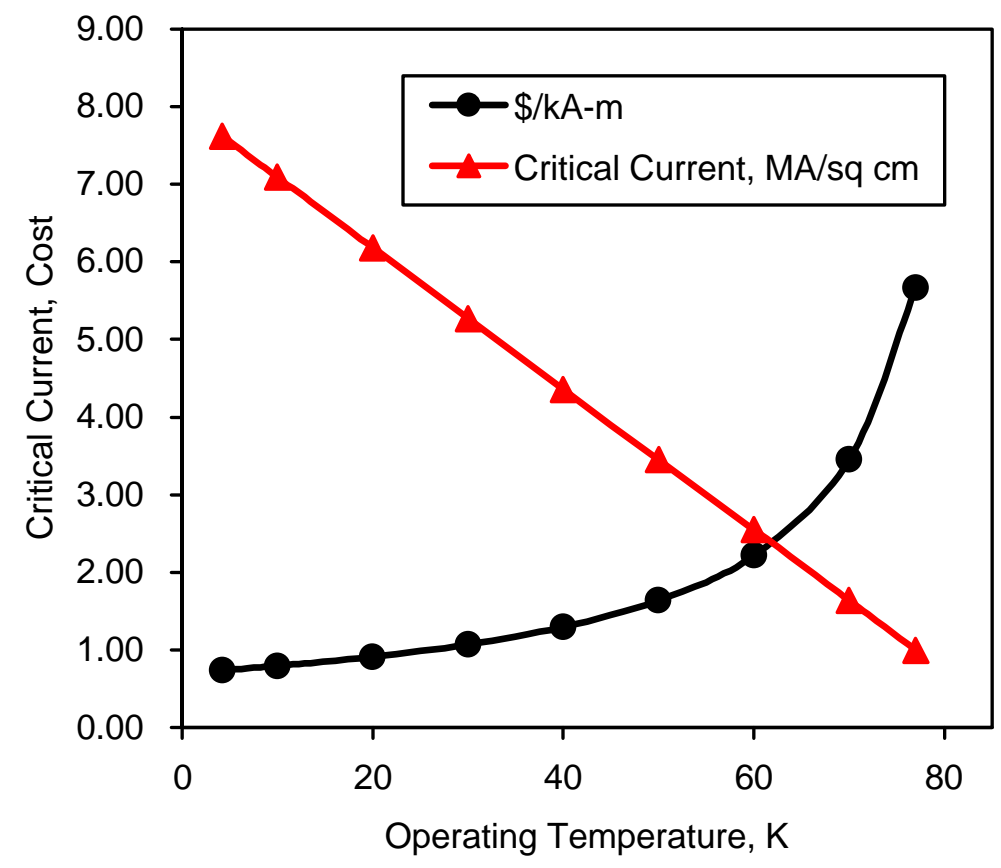

Figure 6.8-1 Cost Sensitivity to Operating Temperature, $B=0$ Case

Similar data are presented in Figure 6.8-2 for critical current density of $10^{5} \mathrm{Amps} / \mathrm{cm}^{2}$ in 5 Tesla flux density parallel to the c-axis at $77 \mathrm{~K}$. Extrapolations to $40 \mathrm{~K}$ and lower are based on extending the data from the reference on a straight-line basis.

The results show a significant decrease in conductor costs at lower temperatures. Overall system life cycle cost analyses for each application should reveal whether this is desirable. 


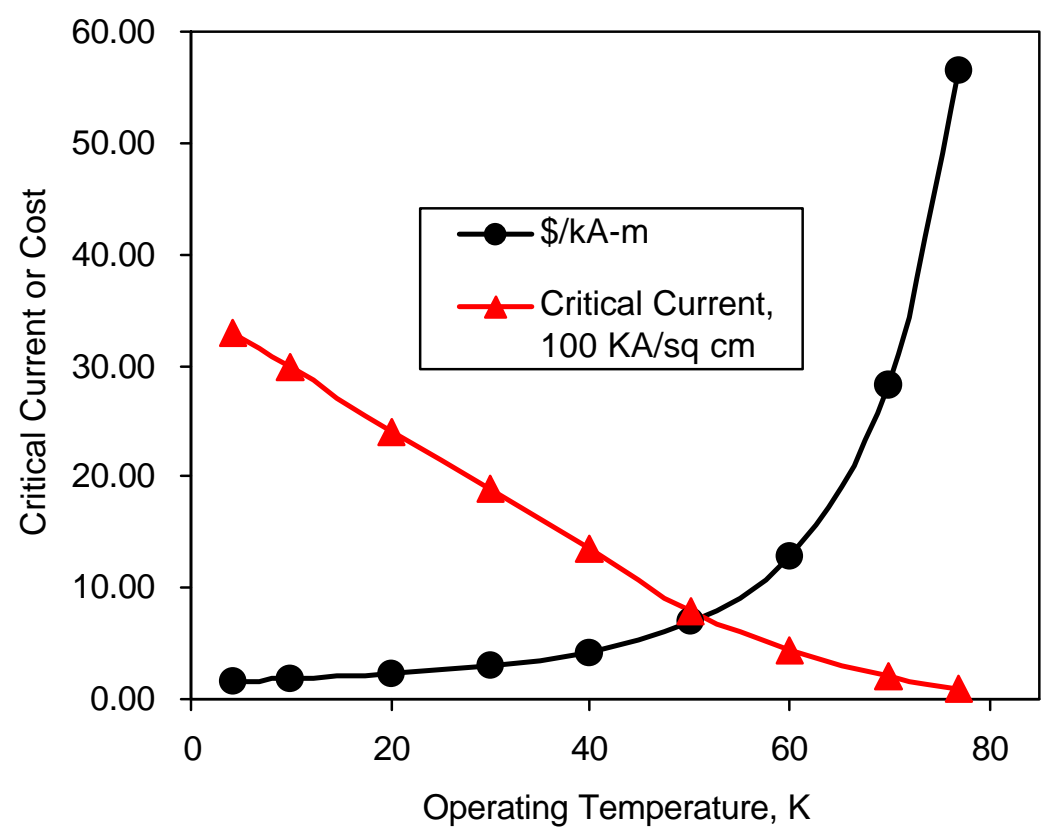

Figure 6.8-2 Cost Sensitivity to Operating Temperature, B = 5T Case

\subsection{Conclusions}

This report provides a framework for evaluating impacts of cost factors involved in manufacture of coated conductors via the MOCVD process. In this process, the primary factors affecting cost are the cost of precursors, the efficiency of utilization of the precursors and the critical current density achieved in the wire produced.

\section{References}

1. Wu, X. D., et. al., "Properties of $\mathrm{YBa}_{2} \mathrm{Cu}_{3} \mathrm{O}_{7-\delta}$ Thick Film on Flexible Buffered Metallic Substrates", Applied Physics Letters 67 (16) October 1995.

2. Goyal, A., et al., "High Critical Current Density Superconducting Tapes by Epitaxial Deposition of $\mathrm{YBa}_{2} \mathrm{Cu}_{3} \mathrm{O}_{x}$ Thick Films on Biaxially Textured Metals", Applied Physics Letters, 69, p. 1795, 1996.

3. Sheth, A. C., et al., Evaluation of Methods for Application of Epitaxial Buffer and Superconductor Layers", Topical Report, DOE/PC/95231-11, University of Tennessee Space Institute, Tullahoma, TN, March 1999.

4. Chapman, J. N. "Life Cycle Cost Study for Coated Conductor Manufacture by Electron Beam and Pulsed Laser Deposition Systems", DOE Topical Report, DOE/PC/95231-16, University of Tennessee Space Institute, Tullahoma, TN, June 1998.

5. Muehlhauser, J. W., Ed., "Research and Development Roadmap to Achieve Electrical Wire Advancements from Superconducting Coatings", Final Draft, prepared for US DOE, July 1997.

6. Oberly, Charles, AFRL, Comments at the DOE 1998 Wire Development Workshop, St. Petersburg, FL, January 30, 1998. 
7. Lee, D. F., et. al., "Alternative Buffer Architectures for High Critical Current Density YBCO Superconducting Deposits on Rolling Assisted Biaxially-Textured Substrates, Jpn. J. Appl. Phys. V. 38 , No. 28 , pp. $178-180$.

8. Yoshida, Y., et. al., "Preparation and Surface Morphology of $\mathrm{YBa}_{2} \mathrm{Cu}_{3} \mathrm{O}_{7-y}$ Films by Metalorganic Chemical Vapor Deposition Block by Block Deposition Using Liquid Sources", Physica C 302 (1998) 31-38.

9. Thomas, M. E., "An Evaluation of Absorption Spectroscopy to Monitor $\mathrm{YBa}_{2} \mathrm{CuO}_{7-\mathrm{x}}$ Precursors for Metal Organics Chemical Vapor Deposition Processing", DOE Topical Report No. DOE/PC/95231-23, University of Tennessee Space Institute, May 1999.

10. Sato, Rikiya, et. al., "Synthesis and Characterization of Ba $\beta$-Diketonate Complexes for Chemical Vapor Deposition of Thin-Film Superconductors", Jpn. Appl. Phys., Vol. 32 (1993) pp. 1590-1594.

11, Chou, P. C. , et. al., "Optimization of $J_{c}$ of YBCO Thin Films Prepared by Photo-Assisted MOCVD through Statistical Robust Design", Phisica C 254 (1995) 93-112.

12. Leskela, M., et. al., "Chemical Vapor Deposition of High $T_{c}$ Superconducting Thin Films", Superconducting Science and Technology, 6 (1993), 635.

13. Wright, A., HAG Development Corporation, personal communication, January 29, 1999.

14. Clean Coal Technology Demonstration Program, Program Update 1998, DOE/FE-0387.

15. Leedham, T., INORGTECH, Personal Communication, February 25, 1999.

16. Jones, R., BOC Gases, personal communication, May 24, 1999. 